\title{
IDENTIFICAÇÃO DOS GENES QUE CODIFICAM PARA A ENTEROTOXINA TERMOLÁBIL LT-II EM AMOSTRAS DE ESCHERICHIA COLI ISOLADAS DE BEZERROS COM DIARRÉIA NA REGIÃO DE JABOTICABAL, SP, BRASIL
}

\author{
IDENTIFICATION OF THE GENES THAT ENCODE FOR THE LT-II THERMOLABILE \\ ENTEROTOXIN AMONG STRAINS OF ESCHERICHIA COLI ISOLATED FROM \\ CALVES WITH DIARRHEA IN THE REGION OF JABOTICABAL, SP, BRAZIL)
}

\author{
Leila Aidar Ugrinovich ${ }^{1}$ Fernando Antonio De Ávila $^{2}$ Maria Natália Oliveira ${ }^{3}$ \\ Antonio Fernando Pestana de Castro ${ }^{4}$
}

RESUMO

Examinando 52 espécimes fecais de bezerros com diarréia de fazendas da região de Jaboticabal, SP, Brasil, uma das amostras de Escherichia coli isoladas, quando analisada pela Reação em Cadeia da Polimerase (PCR), demonstrou a presença dos genes que codificam para a enterotoxina termolábil do tipo LT-II. Este é o primeiro relato de amostra de $\boldsymbol{E}$. coli enterotoxigênica, isolada de bezerros com diarréia no Brasil, contendo os genes para codificação da enterotoxina LT-II. Encontram-se apenas citações de isolamento no Brasil de amostras de $\boldsymbol{E}$. coli LT-II+ de alimentos de origem animal.

Palavras-chave: E.coli, Enterotoxina LT-II, detecção do gene, PCR, Brasil.

\section{SUMMARY}

Examining 52 samples of stools from calves with diarrhea from the region of Jaboticabal, SP, Brazil , one of the strains of Escherichia coli isolated, as examined by the Polymerase Chain Reaction (PCR), harbored the genes encoding for the LT-II thermolabile enterotoxin. This is the first report on the isolation of enterotoxigenic $\boldsymbol{E}$. coli from calves with diarrhea in Brazil harboring the genes for LT-II enterotoxin. In our country, strains of $L T-I I+E$. coli have been reported to occur only in foods of animal origin.

Key words: E.coli, LT-II enterotoxin, gene detection, PCR, Brazil
A colibacilose causada por amostras de $\boldsymbol{E}$. coli enterotoxigênicas (ETEC) afeta principalmente animais recém-nascidos e pós-desmame (ACRES, 1985). Esta enfermidade é responsável por sérios danos econômicos para criadores de gado bovino, no Brasil (CASTRO \& YANO, 1992) e em outros países. (BLANCO et al., 1991, BLANCO et al., 1997).

A patogenicidade das amostras ETEC é devida a produção de fatores de colonização e de enterotoxinas, sendo relatados dois tipos básicos de enterotoxinas, a saber, as termoestáveis (ST) e as termolábeis (LT). Entre as primeiras, conhecem-se dois subtipos clássicos STa e STb, sendo que somente a primeira tem sido encontrada em amostras de ETEC de origem bovina (BLANCO et al., 1993). Entre as enterotoxinas termolábeis, são descritos 2 subtipos LT-I e LT-II. (HOLMES et al., 1986; BLANCO $\boldsymbol{e t}$ al., 1993) As amostras de ETEC de origem bovina não produzem LT-I (BLANCO $\boldsymbol{e t}$ al., 1991), existindo apenas a descrição de amostras produtoras de LT-II (SERIWATANA et al., 1988). Os genes que codificam para a síntese de LT-II já foram clonados e sequienciados (PICKETT et al., 1987) tendo sido descritos iniciadores (SCHULTSZ et al., 1994) para a sua detecção pela reação de PCR.

\footnotetext{
${ }^{1}$ Biologista, doutoranda do Curso de Biologia Molecular e Genética de Microrganismos do Instituto de Biologia da Universidade de Campinas, Campinas, SP.

${ }^{2}$ Professor Titular de Microbiologia, Departamento de Microbiologia e Imunologia da Faculdade de Ciências Agrárias e VeterináriasUniversidade Estadual Paulista, Campus de Jaboticabal, SP.

${ }^{3}$ Biologista, Departamento de Microbiologia, Instituto de Ciências Biomédicas da Universidade de São Paulo (USP), São Paulo, SP.

${ }^{4}$ Professor Titular de Microbiologia do Departamento de Microbiologia, Instituto de Ciências Biomédicas da USP, São Paulo, SP., Autor para correspondência E-mail: apestana@icb.usp.br 
As amostras de fezes coletadas de bezerros com diarréia, com idade variando entre 1 semana a 6 meses de idade de fazendas da região de Jaboticabal, foram semeadas em placas de Petri contendo meio de Ágar MacConkey. Colônias lactose-positivas foram confirmadas como $\boldsymbol{E}$. coli, utilizando os meios de EPM (TOLEDO $\boldsymbol{e} \boldsymbol{t} \boldsymbol{a l} .$, 1982a), MILi (TOLEDO $\boldsymbol{e} t$ al., 1982b ) e citrato (Difco Lab.).

Foram isoladas 52 amostras de $\boldsymbol{E}$. coli, que foram sub-cultivadas em meio de "Trypticase Soya Agar" ( TSA) distribuído em placas de Petri. Estas foram incubadas a $37^{\circ} \mathrm{C}$ por $18 \mathrm{~h}$. Após, da zona de crescimento confluente da placa, foi coletado com o auxílio de uma ponteira um pouco de induto bacteriano, que foi homogeneizado em $500 \mu \mathrm{l}$ de PBS, distribuídos em tubos eppendorf. Esta suspensão foi fervida por 10 minutos, sendo os tubos imediatamente colocados em banho de gelo, para evitar o anelamento do DNA desnaturado. Os componentes da reação, quantidade e concentração final, usados na PCR, por ordem de adição nos tubos reação, se encontram na tabela 1 .

Para evitar reações falso-positivas, as condutas foram realizadas em fluxo laminar, sendo repetido o teste positivo em três ocasiões diferentes. Em todos os casos, todo o material, tais como, luvas, ponteiras e eppendorfs estéreis utilizados no preparo do DNA molde, e de outros reagentes usados na PCR foram dispensados logo após os diferentes procedimentos, para impedir contaminação das bancadas e do fluxo laminar.

Como iniciadores, foram usados os recomendados por SCHULTZS et al., 1993:

LT II-1-5' AGA TAT AAT GAT GGA TAT GTA TC- 3' LT II-2- 5' TAA CCC TCG AAA TAA ATC TC 3,'que amplificam um fragmento de 300 pb. Para a amplificação, foi utilizado um termociclador TM Reseach sendo aplicados 30 ciclos com as seguintes temperaturas: $94^{\circ} \mathrm{C}-1$ minuto (desnaturação); $52^{\circ} \mathrm{C}$ 2 minutos (anelamento); $72^{\circ} \mathrm{C}-1$ minuto (atividade

Tabela 1 - Reação em Cadeia da Polimerase (PCR)- Componentes da reação, quantidade e concentração final, por ordem de adição aos tubos de reação.

\begin{tabular}{lcc}
\hline Componentes & Volume & Concentração final \\
\hline Tampão de PCR 10x & $10 \mu \ell$ & $1 \mathrm{x}$ \\
Mistura de 10mM de dNTP & $2 \mu \ell$ & $0,2 \mathrm{mM}$ cada \\
$50 \mathrm{mM} \mathrm{MgC} \ell_{2}$ & $3 \mu \ell$ & $1,5 \mathrm{mM}$ cada \\
Iniciador A & $8,5 \mu \ell$ & $0,5 \mu \mathrm{M}$ \\
Iniciador B & $7,0 \mu \ell$ & $0,5 \mu \mathrm{M}$ \\
DNA molde & $10 \mu \ell$ & - \\
Taq-DNA Polimerase & $0,5 \mu \ell$ & $2,5 \mathrm{U}$ \\
$\mathrm{H}_{2} \mathrm{O}$ Milli-Q estéril & $59 \mu \ell$ & - \\
TOTAL & $100 \mu \ell$ & - \\
\hline
\end{tabular}

da Taq DNA Polimerase). A amostra produtora de LT-II usada como padrão foi a B62 (gentilmente cedida pelo Prof. J. Blanco, Lugo Espanha), e como padrão negativo, a amostra de $\boldsymbol{E}$. coli K12 (C600). Para a visualização dos resultados, os produtos amplificados foram submetidos à eletroforese em gel de agarose a $1 \%$, com uma diferença de potencial de 100V. O gel foi então tratado em uma cuba de plástico por 20 minutos com brometo de etídio ( $0,5 \mu \mathrm{g} / \mathrm{m} \ell$ ). A observação das bandas foi feita em transiluminador (High Performance Ultraviolet Transilluminator- UVP- Ultra-Violet Products).

$\mathrm{Na}$ figura 1, verifica-se a amplificação do DNA molde da amostra 280, sorogrupo O8 (dados não publicados) que amplificou um fragmento de $300 \mathrm{pb}$, idêntico ao obtido com a amostra padrão LT-II+ (B62) pertencente ao sorotipo O15:H21(Blanco comunicação pessoal).

A ocorrência de amostras de ETEC, produzindo a enterotoxina LT-II, foi descrita em outros países, encontrando-se relatos do isolamento de bovinos com freqüência de 27 amostras LT-II+ entre 36 espécimes fecais examinados (75\%), por PCR. Entre búfalos, foram encontrados 7 espécimes fecais LT-II+, num total de 11 materiais examinados $(64 \%)$. De carne bovina obtida em mercados, $4 \%$ foram positivas para a presença dos genes que codificam para LT-II, sendo que apenas $2 \%$ de fezes humanas foram positivas neste teste (SERIWATANA et $\boldsymbol{a l}$., 1988). Em outra pesquisa realizada na Tailândia, amostras LT-II+ foram encontradas em alimentos de origem animal, mas não foram isoladas amostras LT-II+ de fezes de crianças (RASRINAUL $\boldsymbol{e t}$ al., 1988). Na Espanha, CELEMIN et al. (1994) examinando 118 espécimes fecais de suínos aparentemente normais, encontraram $56(47,8 \%)$ amostras positivas para LTII+ utilizando a técnica de hibridização de DNA.

No Brasil, examinando 96 amostras de alimentos de origem animal, FRANCO et al. (1991) pesquisando 306 colônias, encontraram quatro amostras de $\boldsymbol{E} . c o l i$, isoladas destes alimentos que hibridizaram com sondas específicas para LT-II. Na presente pesquisa, embora a freqüência tenha sido bastante baixa $1 / 52(1,92 \%)$, a amostra LT-II+ foi isolada de bezerros com diarréia.

Diante do exposto, em se considerando as altas frequiências encontradas de amostras de $\boldsymbol{E}$. coli LT-II+ isoladas de animais em outros países (SERIWATANA $\boldsymbol{e t} \boldsymbol{a l}$, 1988), sugere-se que o assunto mereça ser melhor estudado em nosso meio, pois estas amostras de ETEC podem desempenhar papel importante na etiologia da diarréia em bovinos, e o assunto não tem merecido a devida atenção por parte da Vigilância em Sanidade 


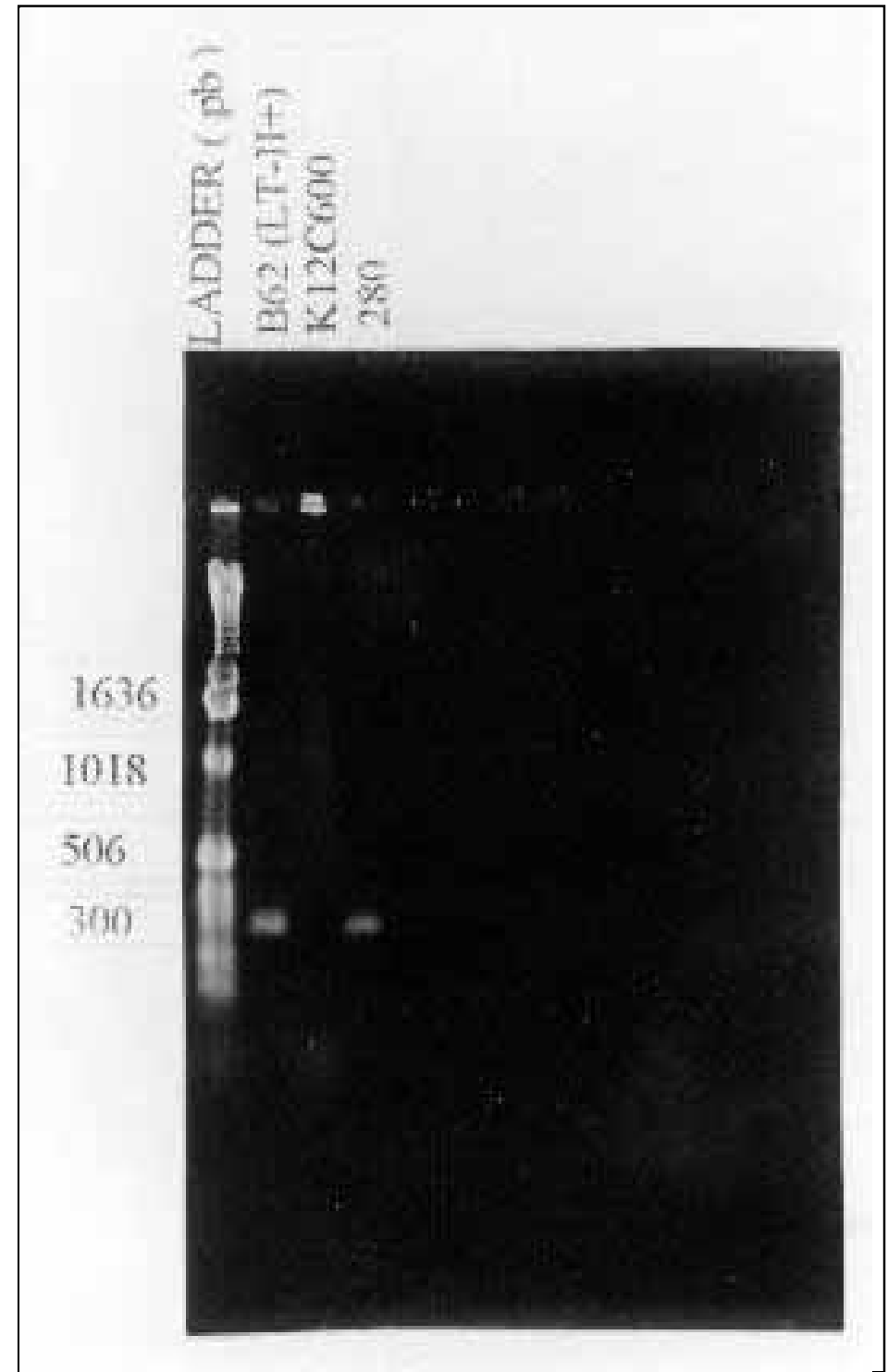

Figura 1 - Resultado do teste de PCR para a amplificação de um fragmento de 300 $\mathrm{pb}$, que identifica os genes que codificam para a enterotoxina LT-II na amostra de Escherichia coli $\mathrm{n}^{\circ} 280$.

Animal. Em relação a humanos, achamos difícil, diante das evidências, supor que amostras LT-II+ possam ser agentes de diarréia no homem.

\section{AGRADECIMENTOS}

Trabalho subsidiado pela FAPESP e pelo CNPq.

\section{REFERÊNCIAS BIBLIOGRÁFICAS}

ACRES, S.D. Enterotoxigenic Escherichia coli infections in newborn calves: a review. J Dai Sci, v.65, p.3547-3555, 1985.

BLANCO, J., BLANCO, M., GARABAL, J.I., $\boldsymbol{e t}$ al. Enterotoxins, colonization factors and serotypes of enterotoxigenic Escherichia coli from humans and animals. Microbiologia SEM, v.7, p.57-72, 1991.

BLANCO, M., BLANCO, J., BLANCO J.E. $\boldsymbol{e}$ t $\boldsymbol{a l}$. Enterotoxigenic, verotoxigenic and necrotoxigenic Escherichia coli isolated from cattle in Spain. Am J Vet Res, v.54, p. 1446-1451, 1993.

BLANCO, M.; BLANCO, J.E.; GONZALES, E. A. et al. Genes coding for enterotoxins and verotoxins in porcine diarrheiogenic Escherichia coli belonging to different $\mathrm{O}: \mathrm{K}: \mathrm{H}$ serotypes. Relationship with toxic phenotypes. J Clin Microbiol, v.35: 2958$2963,1997$.

CASTRO, A.F.P., YANO, T. Diarréia em Bezerros. Coronel Pacheco, MG : EMBRAPA Centro Nacional de Pesquisa. Gado de Leite., 1992. Cap.1: Etiologia bacteriana da diarréia em bezerros: p.2-8.

CELEMIN, C., ANGUITA, J., NAHARRO, G., et al. Evidence that Escherichia coli isolated from the intestine of healthy pigs hybridize with LT-II, ST-Ib and SLT-II DNA probes. Microb Pathog, v.16, p.77-81, 1994.

FRANCO, B.D., GOMES, T.A., JAKABI,M., $\boldsymbol{e} \boldsymbol{t} \boldsymbol{a l}$. Use of probes to detect virulence factor DNA sequences in Escherichia coli strains isolated from foods. Intern J Food Microbiol, v.12, p.333-338, 1991

HOLMES, R.K., TWIDDY, E.M., PICKETT, C.L. Purification and characterization of type II heat-labile enterotoxin of Escherichia coli. Infect \& Immun, v.53, p.464-473, 1986.

PICKETT, C.L.; WEINSTEIN, D.L., HOLMES R.K. Genetics of type IIa heat-labile enterotoxin of Escherichia coli: operon fusions, nucleotide sequence and hybridization studies. J Bacteriol, v.169, p.5180-5187, 1987.

RASRINAUL. L., SUTHIENKUL, O., ECHEVERRIA P.D., et al. Foods as source of enteropathogens causing childhood diarrhea in Thailand. Amer J Trop Med Hyg, v.39, p.97-102, 1988

SCHULTSZ, C., POOL, G.J., van KETEL, R., et al. Detection of enterotoxigenic Escherichia coli in stools samples by using nonradioactively labeled oligonucleotide DNA probes and PCR. J Clin Microbiol, v.32, p.2393-2397,1994.

SERIWATANA, J., ECHEVERRIA, P., TAYLOR, D.N., $\boldsymbol{e} \boldsymbol{t}$ al. Type II enterotoxin-producing Escherichia coli isolated from animals and humans. Infect \& Immun, v.56, p.1158-1161. 1988 .

TOLEDO, M.R.F., FONTES, C.F., TRABULSI, L.R. EPMModificação do meio Rugai e Araújo para realização simultânea dos testes de produção de gás a partir de glucose, $\mathrm{H}_{2} \mathrm{~S}$, urease e triptofano desaminase. Rev Microbiol, São Paulo, v.13 p.309-315, 1982a.

TOLEDO, M.R.F., FONTES, C.F., TRABULSI, L.R. Um meio para a realização dos testes de motilidade, indol e lisina descarboxilase. Rev Microbiol, v.13, p230-235, 1982b. 